Research Journal of Applied Sciences 5 (6): 466-470, 2010

ISSN: $1815-932 \mathrm{X}$

(C) Medwell Journals, 2010

\title{
GIS-Based Site Suitability Assessment for Establishment of Clonal Eucalyptus in Bushenyi District, Western Uganda
}

\author{
Bernard Fungo \\ Department of Forest Biology and Ecosystems Management, \\ Makerere University, P.O. Box 7062, Kampala, Uganda
}

\begin{abstract}
Global demand for wood products is increasing but the forest resources of the world are decreasing. Fast-growing clonal Eucalyptus has been identified as potentially important for establishment of plantations in Uganda for production of poles and timber. The rapid assessment of site suitability based on biogeophysical and socio-economic factors can be complex and time consuming. Using secondary soils, topographic and infrastructure data, this study provides a GIS-based model for rapid site suitability assessments using clonal Eucalyptus as an example.
\end{abstract}

$\underline{\text { Key words: GIS-based model, site suitability, eucalyptus, western Uganda, topographic data, infrastructure data }}$

\section{INTRODUCTION}

Global demand for wood products is increasing but the forest resources of the world are decreasing $(\mathrm{FAO}, 2005)$. Total world round wood production is predicted to grow by 6.6 billion cubic meters by the year 2025 (Sohngen et al., 1997). Some of the demand will be met from managed natural forests but these resources will have diminished due to forest destruction and degradation in the tropics. Several countries have already invested heavily in forest plantations to meet the demand for some forest products especially timber, poles and fuel wood. Chile, New Zealand, Brazil, Spain and Portugal have forest plantations producing round wood for especially eucalypts poles. Plantations in Brazil and Argentina for instance, produce $60 \%$ of the country's industrial round wood but comprise only $2 \%$ of the forest area, (Waggener, 2001). In addition and Brazilian exports account for nearly $2.8 \%$ of the world market for pulp and paper (Sohngen et al., 1997).

Eucalyptus species are known to respond to several conducive and adverse environments, probably explaining their widespread distribution. This makes Eucalyptus a dominant hardwood plantation species (10-15 million ha; Brown, 2000). Since Eucalyptus sp. are widely used in exotic plantations, routine identification of superior clones has become increasingly important (Van der Nest et al., 2000; Sekatuba et al., 2004). Many breeding programs in addition to improving other tree qualities have embarked on developing fast growing tree species like clonal eucalyptus, either through genetic engineering or vegetative propagation of phenotypically superior individuals.
Rationale and significance of the study: The National Forestry Policy for Uganda (MWLE, 2001) draws focus on promoting plantation forestry as one of the ways of preventing reliance on and hence degradation of natural forest for timber and related forestry products if the current and predicted demand is to be met. According to National Agricultural Research Organization (NARO, 2002) and National Forestry Authority (NFA, 2004), fast-growing clonal Eucalyptus has been identified as potentially important for establishment of plantations in Uganda for production of poles and timber. For this reason, Forest Resources Research Institute (FORRI) has adopted fast growing clonal eucalyptus for plantation establishment. Optimizing productivity requires ameliorating crop quality with other requirements in order to arrive at well-suited economic, social and environmental conditions which is in line with NARO's goal of setting up provenance trials for the clonal eucalyptus. Provenance trial sites have been established in different parts of the country to identify suitable provenances for particular agro ecological zones of the country. As a measure to promote plantation forestry in the country this study attempts develop a method to identify suitable sites where these clones could be suitably grown. The objective of this study is to develop a GIS-based model that can be used to determine site suitability for plantation establishment is Uganda.

\section{MATERIALS AND METHODS}

Study area: Bushenyi district was a preferred site for this study because of the high rate at which tree planting is going on. The boundary map of the study district was 
obtained by digitizing it from the map of Uganda (Fig. 1). Using this boundary map as the clip layer, soil mapping units, roads, towns and contours of the study area were clipped form the respective national maps.

Approach: Digital data used included; soils attribute data (available phosphorus, organic matter, $\mathrm{pH}$, clay content) and topography (elevation). These data were obtained from the Soil Science Department, Makerere University. Save for elevation, each of the above conditions were grouped into three classes-high, moderate and low suitability suitable for the growth of eucalyptus. Sites such as lakes and permanent swamps did not have soils

Location of Bushenyi district, Western Uganda

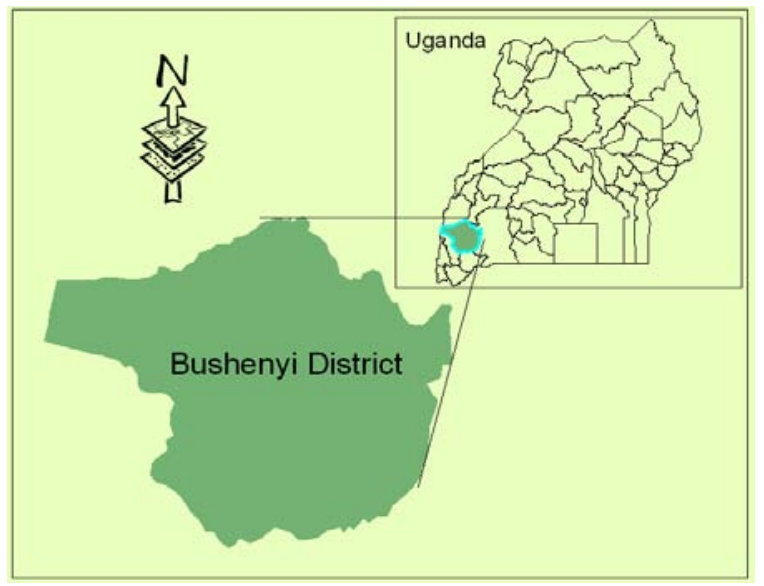

Fig. 1: Location of Bushenyi district, western Uganda data and were marked as unsuitable. Data on infrastructure such as road network and towns were used to eliminate areas that cannot be used for tree planting. The Fig. 2 shows the approach used to arrive at the site suitability map.

Available spatial data of soil mapping units was enriched with attribute soil properties $(\mathrm{pH}$, silt, clay, phosphorus and organic matter) from the Memoirs of the Research Division, Uganda Protectorate, 1963. Because of the limitations of analyzing extensive data, other soil properties were left out. However, the selected properties are major indicators of factors affecting plant growth and reflect the potential of others soil properties. For example,organic matter and $\mathrm{pH}$ are important in determining availability of most micronutrients and are therefore good indicators of soil quality (Brady and Weil, 2002; Havlin et al., 2005). Climatic variables (rainfall and temperature were not considered in the suitability map because there is only one weather station from which data are collected and is generalized for the whole district. Therefore, the climatic factors of all areas within the district were, on average, considered to be the same. Including Infrastructure (urban areas and roads) aimed at excluding areas that cannot support tree growing.

\section{Procedure}

Soil suitability maps: Maps of each of the soil properties were developed by creating a new empty shape file and later transferred to the map document containing the soil map units in the study area. In each map unit, at least one

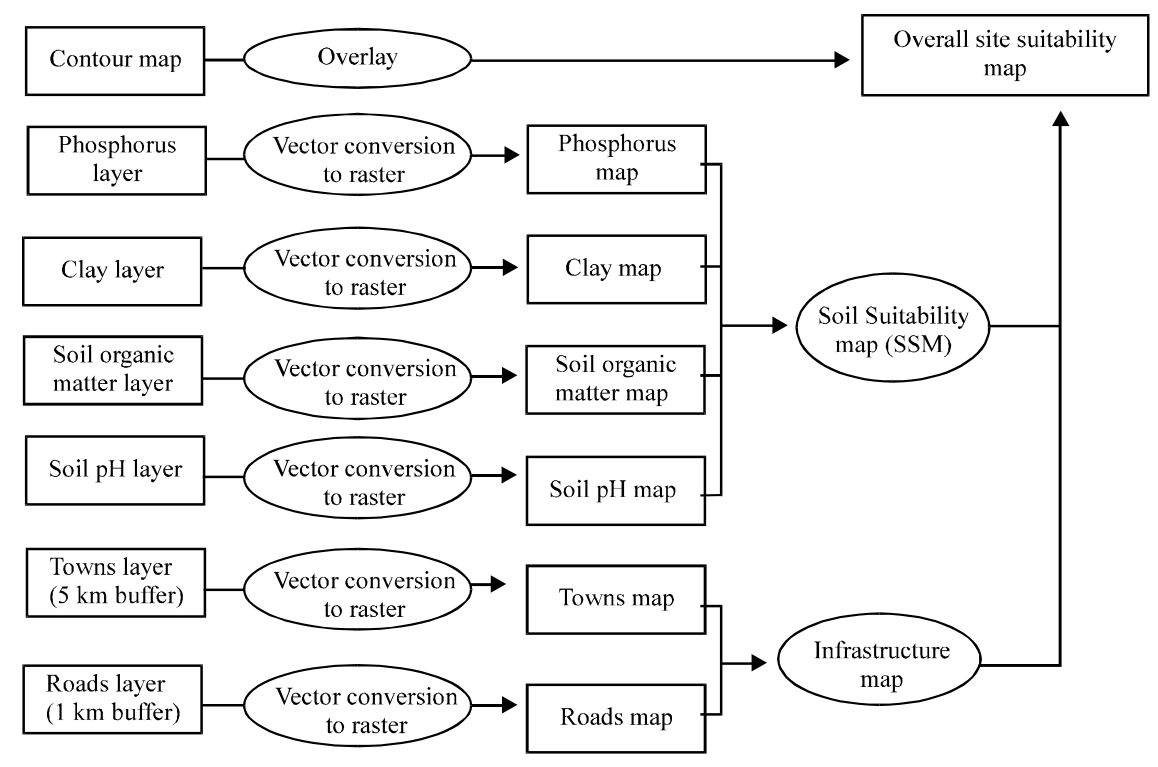

Fig. 2: Logical framework for site suitability map 
point was digitized but one map units was large and had two points taken from it. In total, there were 16 soil mapping units in the area and a total of 17 points were digitized. It real terms, the spatial data should be the location of the point at which the sampling for characterization of the soil properties is done. Attribute data on soil properties were entered into the attribute table of the newly created point layer. Soil properties maps were created by performing ordinary kriging on each of the soil properties. Each map was then converted to raster format before reclassifying into the suitability classes (high, medium and low). It is important to note that for kriging to be done the data points should be $>90$ for most GIS models. Otherwise, use of splines or Inverse Distance Weighting (IDW) are preferred methods for such small data points.

Infrastructure maps: Major roads were buffered at $1 \mathrm{~km}$ to allow for road reserves and avoid competition by other commercial investments such as shops and settlements that are more profitable.

Towns were buffered at $5 \mathrm{~km}$ because the costs of land near the town center may be too high to allow meaningful investment in tree plantations. This buffer also eliminates the possibility of changing land use from tee plantation to urban land use as a result of increasing urban development before the plantations reach their rotation age. Buffered infrastructure maps were converted to raster format before reclassifying into two suitability classes.

Merging maps: Soil property maps were merged using the raster calculator in ArcMap. Weights were subjectively allocated to each soil property based on the assumed importance to tree growth using the raster equation below:

$\mathrm{pH}^{*} 0.3+$ Organic matter ${ }^{*} 0.3+$ phosphorus ${ }^{*} 0.2+$ Clay $^{*} 0.2$

The infrastructure maps were merged using the raster equation:

$$
\text { con }[(\text { Roads })=1,1,0+(\text { Towns })=1,1,0]
$$

where, $1=$ Suitable and $0=$ Unsuitable. The importance of the properties selected should always be based on realistic values obtained from, for example research in the field or from literature. The properties vary from crop to crop. To arrive at the final site suitability map, the infrastructure map was overlaid on the soils suitability map and the colour of the unsuitable area was made the same as that of the infrastructure. The contour map was also overlaid on the final map to show the relationship between suitability classes and topography.
Limitation of the data: Data available was generally old (1963). Several changes in soil properties are expected because the area is covered by steep slopes that induce runoff and erosion. The scale at which data were collected is generally small $(1: 250,000)$. However, since eucalyptus, like other trees can generally survive harsh conditions compared to agricultural crops, the changes so far may not amount to causing total failure of the tree crop.

Therefore, this information may be good enough to guide general decision making about suitable sites for clonal eucalyptus tree planting project. An important data limitation was the absence of land use data that could have been useful in identifying unsuitable locations such as the National Park lying on the western border of the district.

Besides this, experience from a previous visit to the area indicates that there are no other areas that require special consideration in this matter. Therefore, all areas included were generally considered potential for clonal eucalyptus.

\section{RESULTS AND DISCUSSION}

Of the suitable site, the highly suitable areas were the largest in extent, followed by moderately and least the low suitability site (Fig. 3).

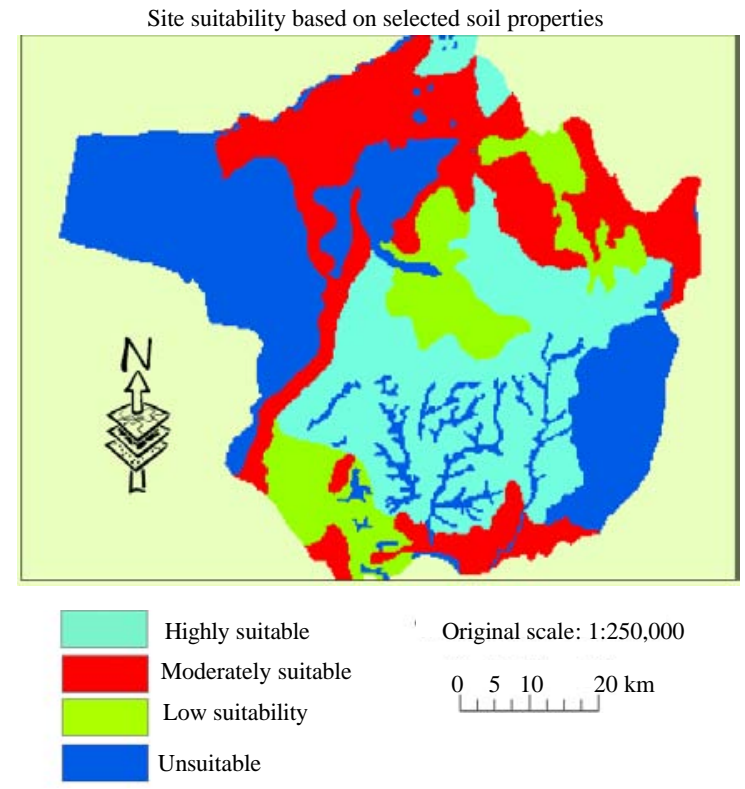

Fig. 3: Suitability map of Bushenyi district based on selected soil properties. Spatial data: soils, roads and towns-Department of Soils Science. Makerere University. Attribute data-Research MemoresSoils Division, 1963. Map by Bernard Fungo 


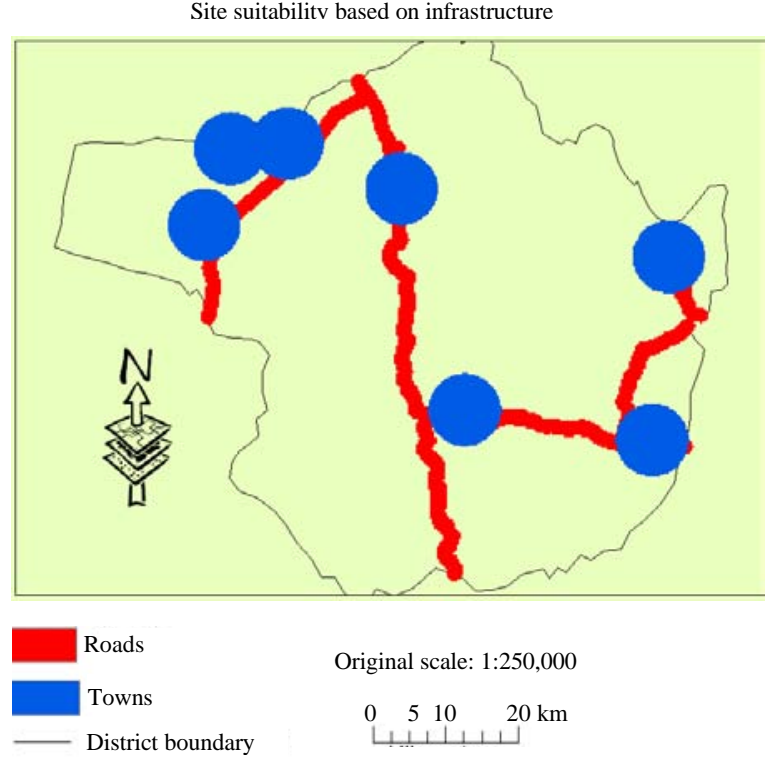

Fig. 4: Suitability map of Bushenyi district based on infrastructure Spatial data: soils, roads and townsDepartment of Soils Science. Makerere University. Attribute data-Research Memores-Soils Division, 1963. Map by Bernard Fungo

Site suitability for clonal eucalyptus plantations in Bushenyi district, Western Uganda
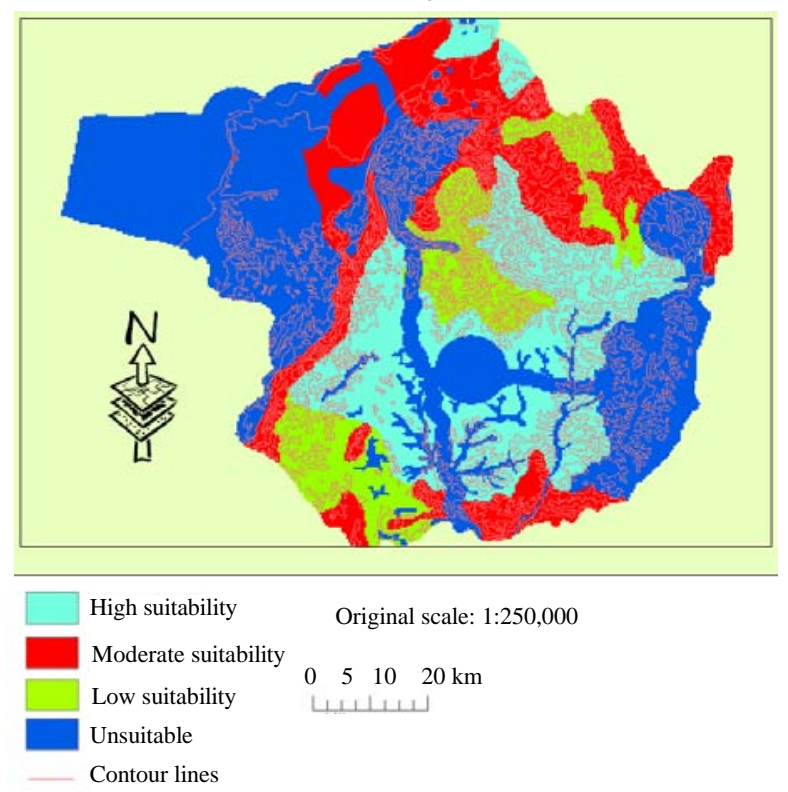

Fig. 5: Overall site suitability map for of Bushenyi district. Spatial data: soils, roads and townsDepartment of Soils Science. Makerere University. Attribute data-Research Memores-Soils Division, 1963. Map by Bernard Fungo
The unsuitable areas comprises mainly of the Lake George in the western side and a permanent swamps in the south east of the district. The roads and towns are located in highly suitable areas (Fig. 4) and seem to fall mainly in the high and moderately suitable areas.

Comparing soils suitability map (Fig. 3) and the infrastructure map (Fig. 4) shows that the towns are located in areas that are either highly or moderately suitable land.

The contour map overlaid on the site map (Fig. 5) shows that the area is generally hilly and some of the highly fertile areas are located in the lower slopes. It is also possible to improve visul quality by using surface analysis instead of contour lines. This was not possible because of software limitations.

\section{CONCLUSION}

The large extent of highly suitable areas is evidence that Bushenyi district is one of the most fertile areas in the country. Its soils are generally ferallitic developed from gneisis quartznic, chists and granulates and have metamorphic deposits. According to Aniku (2001) they are deep with little differentiation into clearly defined horizons.

Although, some areas have low suitability for clonal eucalyptus, they are small in extent. Unsuitable areas comprise mainly built up areas in form of towns and roads, lakes and permanent swamps. The areas that are highly suitable are also surrounding towns and this is probably because of the inherent fertility that drew settlement. This puts question on the success of tree planting program as there is likely to be rapid land use change to urban. The fact that the area is generally steep and thus susceptible to erosion could explain why highly suitable areas are locates predominantly at the lower areas settlements. The lower slopes are enriched with silt deposited after erosion. This is the same reason why settlements are located in these areas.

\section{RECOMMENDATIONS}

The GIS-bases site suitability assessment model is a suitable and quicker way of analyzing suitability based on multidimensional criteria (soils, topography, demography and infrastructure). Its predictive capability will depend on the criteria selected, rating of suitability and the quality of data used to derive the model. Further investigations should be sought on the possibility of using this approach in a participatory manner with other decision makers (farmers, extension workers, private sector and policy makers). 


\section{REFERENCES}

Aniku, J., 2001. Geology. In: Agriculture in UgandaGeneral Information, Mukiibi, J. (Ed.). Vol. 1, NARO, Uganda.

Brady, N.C. and R.R. Weil, 2002. The Nature and Properties of Soils. 13th Edn., Prentice Hall, New Jersey, ISBN: 0130167630.

Brown, C., 2000. Global forest products outlook study: Thematic study on plantations. Working Paper No. GFPOS/WP/03. FAO, Rome, pp: 129.

FAO, 2005. State of the Worlds Forests. FOA, Rome, pp: 153.

Havlin, J.L., J.D. Beaton, S.L. Tisdale and W.L. Nelson, 2005. Nitrogen, Soil Fertility and Fertilizers. 7th Edn., Prentice Hall, New York.

MWLE, 2001. The Uganda Forestry Policy. Ministry of Water, Lands and Environment, Uganda, pp: 29.

NARO, 2002. Annual Report. NARO, Uganda.

NFA, 2004. The Forester. National Futures Association, USA.
Sekatuba, J., J. Kugonza, D. Wafula, W. Musukwe and J. Okorio, 2004. Identification of indigenous tree and shrub species in the lake Victoria shore region of Uganda. Uganda J. Agric. Sci., 9: 372-378.

Sohngen, B., R. Mendelsohn, R. Sedjo and K. Lyon, 1997. An analysis of global timber markets. Resources for the Future, Discussion Paper 97-37. http://ideas.repec. org/p/rff/dpaper/dp-97-37.html.

Van der Nest, M.A., E.T. Steenkamp, B.D. Wingfield and M.J. Wingfiled, 2000. Development of simple sequence repeat (SSR) markers in Eucalyptus from amplified inter-simple sequence repeats (ISSR). Plant Breed., 119: 433-436.

Waggener, T., 2001. Role of plantations as substitutes for natural forests in wood supply-lessons learned from the Asia-Pacific. Forest Resources Development Service Forest Resources Forestry Department Division Working Paper FP/7, FAO, Rome, Italy. 